Article

\title{
Prioritizing the Chicken or Egg? Electric Vehicle Purchase and Charging Infrastructure Subsidies in Germany
}

\author{
Roland Zink *, Javier Valdes and Jane Wuth \\ Institute of Applied Informatics, Deggendorf Institute of Technology, 94078 Freyung, Germany; \\ E-Mails: roland.zink@th-deg.de (R.Z.), javier.valdes@th-deg.de (J.V.), jane.wuth@th-deg.de (J.W.) \\ * Corresponding author
}

Submitted: 15 March 2020 | Accepted: 8 August 2020 | Published: 11 September 2020

\begin{abstract}
To meet current targets for greenhouse gas emissions in Europe, emissions, especially those originating from the road transport sector, need to be reduced. Plans are to achieve this goal by substituting fossil fuel vehicles with electric vehicles (EVs). This article first discusses conceptually the impact of an increasing share of EVs on the electricity grid and suitable locations for charging stations with examples from a Case Study in Lower Bavaria. Secondly, the impact of purchase subsidies on EV purchases in Germany, a high-income country characterized by an important automotive industry and an increasing share of private vehicles is examined. To achieve this, yearly information on EV purchases were analyzed by applying the Synthetic Control Method. Combining data from different sources including the European Alternative Fuels Observatory, Eurostat, and the European Automobile Manufacturers' Association, an overall picture was developed. Results indicate a difference between private, semi-public, and public charging infrastructures. Its spatial distribution does not correspond to a specific development strategy. Moreover, EV subsidies have a limited effect in Germany when controlling for market size. Limiting the discussion to a trade-off between subsidizing infrastructures or EV purchases obviates the multidimensionality of the problem as neither of them may be sufficient to accelerate the transition per se. Furthermore, if electricity provided for EVs comes mainly from fossil carriers, the changes in the road transport sector will not yield the expected emission reductions. The transition towards renewables is directly intertwined with the effects of EVs on emission reductions in the road transport sector.
\end{abstract}

\section{Keywords}

electric vehicles; energy policy; fossil fuels; Germany; green energy; subsidies; transportation

\section{Issue}

This article is part of the issue "Politics and (Self-)Organisation of Electricity System Transitions in a Global North-South Perspective" edited by Eberhard Rothfuß (University of Bayreuth, Germany) and Festus Boamah (University of Bayreuth, Germany).

(C) 2020 by the authors; licensee Cogitatio (Lisbon, Portugal). This article is licensed under a Creative Commons Attribution 4.0 International License (CC BY).

\section{Introduction}

Policy and climate strategies in several countries give electric mobility an important role in reducing $\mathrm{CO}_{2}$ emissions to achieve national and international goals such as the Paris Agreement (United Nations, 2015). This reduction is planned to be mainly driven by the substitution of fossil fuel vehicles with electric vehicles (EVs), but it requires millions of drivers to invest in fleet renewal (Riesz, Sotiriadis, Ambach, \& Donovan, 2016). A critical discussion about EV adoption and its contribution to reducing greenhouse gases is required. To avoid the wellknown costly externalities of coal and nuclear power, governments are subsidizing the use of greener technologies which can reduce these negative externalities. In Europe, policies to support EVs vary from region to region and include purchase tax extensions, reduction and exemption of registration taxes, free parking, preference in bus lanes, and even subsidies for the purchase of EVs (European Alternative Fuels Observatory, 2020). By do- 
ing so, governments aim to increase the number of early adopters by creating niche markets with which EV manufacturers can generate revenue to foster new dynamics, such as economies of scale (Geels, 2002).

However, EVs are not a solution by themselves. A thorough assessment of the EV life cycle regarding the energy, greenhouse gases emissions, and materials linked to the power generation mix of electricity used to charge the EVs (Girardi, Gargiulo, \& Brambilla, 2015) is necessary. The first aspect addresses the technology used within vehicles, especially the battery, and innovations in materials and production. The power generation mix of electricity used to charge EVs as the second aspect shows large regional and national differences. Among other things, the power generation mix and the contribution of renewable energy depend on the natural potential of a region and political energy strategies. Greenhouse gases emissions from EVs are very different between France, whose power generation mix has a high share of nuclear energy, and Germany which has rapidly increasing renewable energy resources and a politically decided phase-out of nuclear and coal. The variety of possible socio-technological scenarios and the technical complexity involved in charging EVs with renewable energy is represented by the number of studies on the subject (see, for a more recent review, Rae, Kerr, \& Maroto-Valer, 2020; Richardson, 2013).

In Germany, despite the enormous expansion in recent years, renewable energy resources currently contribute $40.2 \%$ to the gross power generation (AG Energiebilanzen e.V., 2020). Since at the same time the share of coal electricity is still high (around 38\% in 2018), the corresponding $\mathrm{CO}_{2}$ reduction potentials of the power sector and thus EVs has not yet been fully exhausted. Although the number of EVs has steadily increased in recent years, the conversion rate from fossil fuel vehicles to EVs remains steady as the overall number of privately owned cars in Germany grows (KBA, 2020). Even though the conversion of fossil fuel vehicles to EVs reduces the primary energy demand due to the much higher efficiency of an electric motor (Sovacool \& Hirsh, 2009), the further expansion of renewable energy resources remains a basic requirement for electric mobility to meet the goal of climate-friendly mobility.

In addition to the substitution of fossil fuels by renewable energy sources, the technological innovation and expansion of electric mobility requires a great deal of investment, both in vehicles and charging infrastructure. In a study of the EV market in Nordic European countries, Kester, Noel, de Rubens, and Sovacool (2018) and Kester, Sovacool, de Rubens, and Noel (2020) find that the cost of EVs is one of the most important barriers to their adoption. Internal combustion vehicles are cheaper than EVs which makes the latter be perceived as a luxury product. For this reason, governments around Europe have established incentive programs for EVs (European Alternative Fuels Observatory, 2020). But the transition to electric mobility also requires a change in the charging infras- tructure. Due to the orientation towards the existing traffic infrastructure, fossil fuel stations are available nationwide and built at central locations with small catchment areas. With the transformation towards EVs, mobility is moving more and more into the everyday life of people as the infrastructure is scarce and more oriented towards people's daily lives, consumption, and working hours.

In Germany, the power grid is not fully decentralized, meaning supplied by several energy sources across the country to fulfil every customer's demand for electricity and to reduce losses due to long-distance transfer. Such a decentralization process takes place but will reorganize the fueling processes, such that fueling can take place where drivers spend more time: at home, at work, or at their places of consumption and leisure. This article discusses the spatiotemporal changes towards electric mobility conceptually and differentiates between the categories of private, semi-public, and public space. In this context, a sustainable and user-oriented charging infrastructure is understood to be the essential requirement for any further expansion of electric mobility. This is especially true as, in addition to the high costs of EVs, range anxiety, and the poorly developed charging infrastructure are understood as the main obstacles to change (Sovacool, 2017). Nevertheless, in this transformation process, for many countries, the question remains as to what must be given preference: the chicken or the egg? More EVs can justify the (economic) need for a nationwide charging station (CS) network and could enhance private investment in the charging infrastructure development. The support for a gapless network of CSs, on the other hand, would enable electric driving in a practical nationwide manner and could, by reducing range anxiety-a main inhibitor for EV purchasessubstantially increase EV sales. In Germany, one of the countries with well-developed charging infrastructure, the small number of EV charging events in most regions, results in most CSs not being profitable. The analysis presented here shows that neither a well-developed charging infrastructure nor an EV subsidy policy may be sufficient to accelerate the transition in Germany. These results have important implications for studies in the area of electro-mobility as they highlight the need to explore other dimensions with a less technoeconomic perspective.

The present work provides an overview of the current EV literature in Section 2. Section 3 discusses spatial patterns of the new electric charging infrastructure followed by an examination of direct subsidies to EV purchases in Germany in Section 4. Section 5 concludes.

\section{State of the Art}

The development of the charging infrastructure is closely linked to the adoption and acceptance of EVs. The modelling of the charging infrastructure is of paramount importance in the electrification of the transport system since it delimits the mobility associated with the vehi- 
cles. For this reason, while one part of academic research focuses on surveys to analyze trends in acceptance rates or changes in perceptions (e.g., Lieven, 2015), others build upon these results and try to find out how EV adoption can be intensified. Nearly all authors state that purchase subsidies are most important for EV adoption, some describing it as the single impacting incentive. Others explain how purchase subsidies do not incentivize consumers enough, so that post-purchase incentives are necessary. Again, others state that the charging infrastructure is also of major importance. Rohr et al. (2017) for example focused on the evaluation of two surveys in France, Germany, Italy, the UK, Poland, and Spain in 2012 and 2016. The key hurdle for the acquisition of EVs identified was the high price compared to common fossil engines. Other purchase inhibitors were the lack of infrastructure, the limited driving range, and the lack of diversity in model choice. Comparing the results of 2016 with the ones from 2012, people perceive the reduced operating costs of EVs more strongly and appreciate its economic benefit more. More people state they do not know whether there is an environmental benefit. However, even if the key issue in deciding whether or not to buy an EV is still the high purchase price, the perception that they are very expensive has decreased. Purchase price subsidies thus probably have an effect not only on the purchase price but also on the perception of the price to the people. Langbroek, Franklin, and Susilo (2016) compared two different strands of policies by evaluating their respective effectiveness. With rising policy costs, the effectiveness of the same may increase. Use-based incentives such as allowing the use of bus lanes or free parking spaces are not costly, yet also yield lower increases in purchase numbers than the much more expensive purchase subsidies. Research shows that the users' willingness to buy EVs is not only dependent on policies but also on the characteristics of the existing charging infrastructure and that personal perceptions are also relevant.

The analysis of EV purchase rates is influenced not only by subsidies for EVs and CSs infrastructure development but also by oil prices, for example. The higher the price of oil, the more attractive are the lower maintenance and operating costs of EVs, which explains the overall change in the perception of an EV's costs. Additionally, even though the perception of environmental friendliness of EVs decreased in 2016 compared to 2012, it still is a very important factor for customers when buying EVs. Still today, most purchases of EVs are based on the dilemma between wanting to drive a modern car and the increasing understanding of the need to protect the environment. Most vehicle brands offer vehicles purely driven by electricity called 'battery electric vehicles' (BEV) and 'plug-in hybrid electric vehicles' (PHEV), that combine a combustion engine with an electric motor. In PHEVs, when the charged electricity is used up, the combustion engine takes over and the vehicle operates as a conventional, non-PHEV. This helps to mitigate users' range anxiety and inefficiencies in the poorly developed charging infrastructure (Sovacool, 2017). Nevertheless, the number of EVs on offer is very low compared to combustion engines vehicles; in 2015, only 27 BEV and 26 PHEV vehicle types were available in the European market, their costs being at least $40 \%$ higher than a comparable conventional car. Lin and Sovacool (2020) when analyzing the market dynamics of the BEV vehicle market in Iceland, observed an inter-niche competition between $\mathrm{BEV}$ and PHEV, which may be related to the limited driving range and CS network development.

The transformation towards electric mobility creates completely new spatial patterns of fueling infrastructure. Therefore, several publications on the modelling of optimal locations for electric CSs have emerged. Pagany, Ramirez Camargo, and Dorner (2018) and Wirges (2016), give a broad overview of different spatial localization methodologies published in recent years. Location models are necessary to plan the transformation and rethink spatial patterns of the charging infrastructure. For example, GIS-based approaches offer the opportunity to find spatial hotspots for CSs and to discuss them in terms of public funding measures, spatial planning, or with a view to the power supply network and the provision of renewable energy. Spatial or geostatistical approaches like in Andrenacci, Ragona, and Valenti (2016) or Campaña and Inga (2019) are often applied. The planning of CS deployment leads to mitigate range anxiety, ensuring EVs provide similar performance to those using the internal combustion engine. Most CS planning applications try to locate the CSs where the travel demand is concentrated. However, although there are many models in practice, the CSs are installed in an uncoordinated way. These installation patterns, which may be affecting demand for BEVs, have not been studied so far.

The two strands of literature, charging infrastructure and EV market size, are highly intertwined. Nevertheless, the direct research of both topics in combination is tricky and not yet sufficiently analyzed. Moreover, the adoption and acceptance of EVs have mostly been researched using econometric models based on the assumption of there being large amounts of data available, which is not the case due to the novelty of this market and the recent rapid expansion of EVs. To better combine the two topics and to consider the relationship between them, this article applies the synthetic control method of Abadie and Gardeazabal (2003) to understand the impact of EV purchase subsidies.

The evaluation of public policies using synthetic controls is an area of research that has recently stood out for its innovation (Athey \& Imbens, 2017). This area of research is based on the comparison of the evolution of variables of interest between the entity affected by the public policy intervention and a control group. Unlike classical policy studies, the synthetic control method is based on the observation that a combination of untreated units (i.e., a 'synthetic control unit') can provide a closer approximation to the characteristics of the unit affected by the intervention than any individual unit. In 
the context of this comparative study in which there is a small sample with interventions at the aggregate level (countries and states), it is fundamentally complex to find adequate controls that have not been affected by the intervention and that possess characteristics similar to those of the intervened unit (Abadie, Diamond, \& Hainmueller, 2010). This problem is well known in the discipline and has always caused researchers to do more comparative case studies (Collier, 1993; Lijphart, 1971). However, the synthetic control method excels in cases where there are too few observations to make an assessment using other statistical techniques (Abadie \& Gardeazabal, 2003), which is why the topic discussed here is a perfect fit for this method.

\section{Spatial Pattern of Electrical Charging Infrastructure}

While the charging process for a car powered by fossil fuels (petrol, diesel, gas) is highly standardized worldwide,
CSs are more complex. Different charging modes allow flexibility in terms of time, which means that the charging process can be integrated differently into the existing supply structures and everyday life. This has been seen as an opportunity to build electric charging infrastructures independently of existing structures, however, with an increasing penetration rate of EVs it would require smart grids and the regulation and control of existing electrical infrastructure. This transformation strongly influences the spatial design of the charging infrastructure, which is why it makes sense to distinguish conceptual variants regarding the spatial division into private, semi-public, and public spaces. A key success parameter will be how the charging infrastructure, described and graphically visualized (Figure 1) below, can be integrated spatially and temporally into the current traffic system as well as into the electric supply system.

The CS infrastructure is context-dependent: Differences between rural and urban areas have to be taken

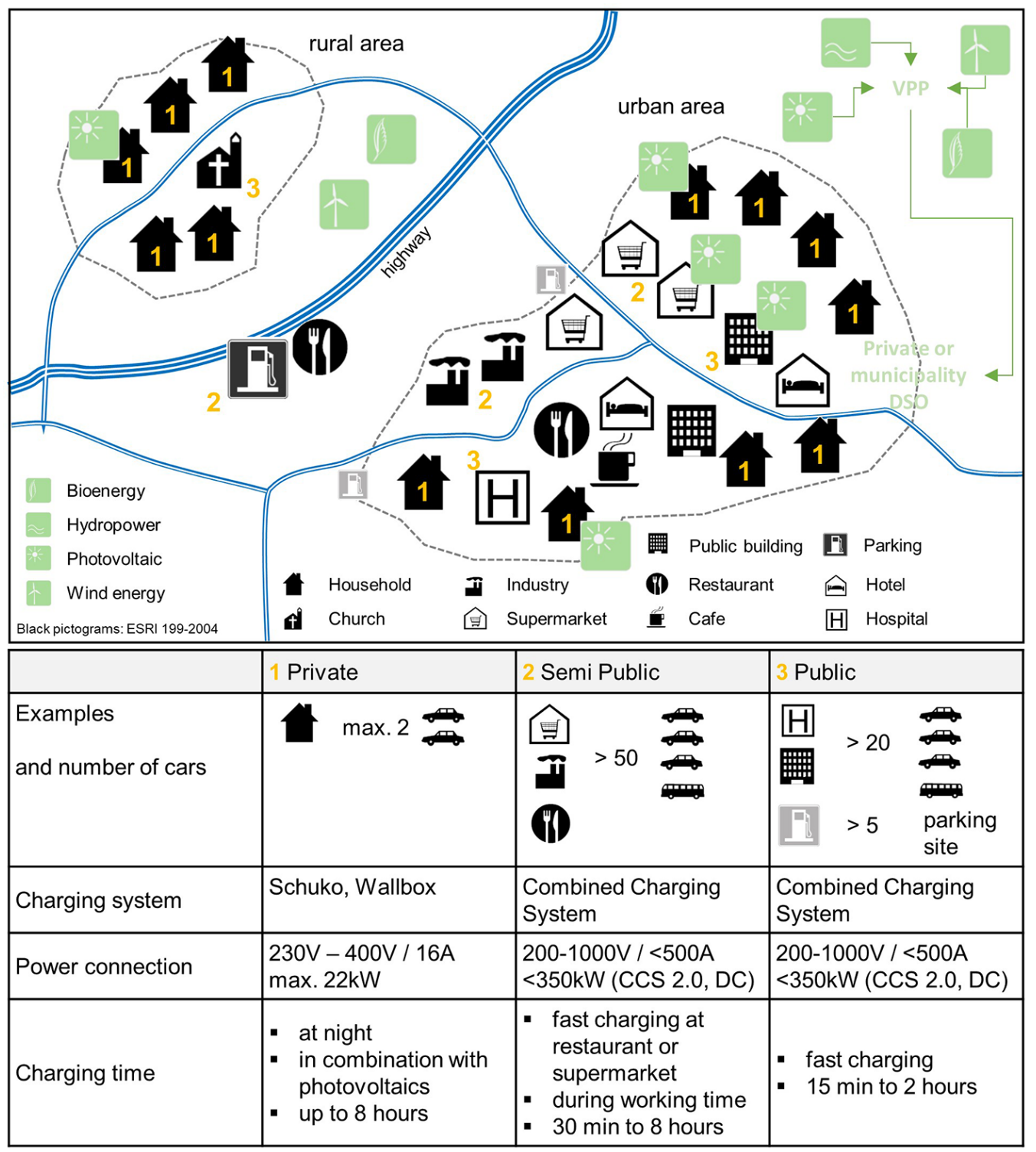

Figure 1. Spatial pattern of the electric charging infrastructure. 
into account as the different population densities or the different economic activities, generate variation in the number of CS needed and overall electricity demand. Moreover, in an urban context, there is a need for closer integration with local public transport, whereas in rural areas, individual transport is more significant. Finally, an orientation towards the needs of the people and an appropriate integration into their everyday life is required in both types of regions. Figure 1 conceptualizes this approach and shows that the spatial structure is evolving from the few conventional petrol stations, predominantly along primary roads or motorways, to fullcoverage possibilities for charging. In the private context, the provision of energy can be achieved by e.g., using small photovoltaic systems or other decentralized renewable energy resources as a maximum of two cars per household usually have to be charged. In public and semipublic parking sites, the number of CSs increases, which also means that a larger energy capacity is required. That is why local or national electricity suppliers mostly take care of the supply. In order to achieve the goals of climate-friendly mobility, power must be provided by a low-carbon or de-carbonized power sector with high proportions of renewable energy (Die Bundesregierung, 2009 , p. 8), e.g., combined in a virtual power plant (Figure 1). Therefore, in addition to the charging infrastructure, it is also necessary to change the power generation mix, which implies a spatial transformation with new spatial patterns (i.e., Blaschke, Biberacher, Gadocha, \& Schardinger, 2013; Bosch, Rathmann, \& Schwarz, 2019; Zink, 2015).

\subsection{Private Context}

Refuelling at home is a completely new option that is made possible through electric mobility. With a correspondingly expanded electric infrastructure available in all industrialized countries, electric mobility infrastructure is added to the household, making households consumers of both EVs and CSs. Charging is possible via conventional power connections (in Germany mostly Type C and Type F [Schuko]; International Electrotechnical Commission, 2020) or by installing so-called wall boxes. Using Schuko, however, the charging process takes sev- eral hours due to the low charging power, whereas wall boxes (Figure 2) can significantly reduce the charging time; in both cases, the domestic power connection is usually sufficient.

The charging time depends on the downtime of the cars. Since a full charge in these stations requires several hours and charging is usually done at night, the need for fast charging infrastructure is not mandatory. Consequently, large fluctuations in electricity consumption are avoidable. In addition, the intelligent combination with consumers' own power generation is possible, for example, by using rooftop photovoltaics in combination with local storage systems, which offsets the additional local demand for electricity. With their large batteries, the EVs can themselves take on a storage function for the household.

\subsection{Semi-Public Context}

The semi-public area refers to charging points installed in private spaces that can be used by a large number of people. These are primarily company parking (Figure 3) sites as well as parking sites for supermarkets, malls, restaurants, cafes, or other private but commercially used parking sites. The number of CSs depends on the company or institution providing this semi-private parking and their frequency of visitors. The loading times vary from a few minutes when shopping in the supermarket to several hours at company parking sites. The charging points are mainly visited during the day and their use is based on the opening hours of each facility. Parking (and loading) can be limited in time. The charging of EVs can be provided by the owner of the parking areas either as a free service or as a new fee-based service.

Currently, electric CSs are still a rarity in semi-public parking sites. The Verband der Automobilindustrie (2019) reported that, in 2019, German retailers installed over $1,000 \mathrm{CSs}$ in semi-public areas and that semi-public and public locations currently account for $15 \%$ of the charging infrastructure available. Nevertheless, as in the example (see Figure 3) of a technology-oriented business park and business incubator Innovations Technologie Campus Deggendorf (ITC 2), companies use the charging infrastructure primarily for image and marketing purposes to

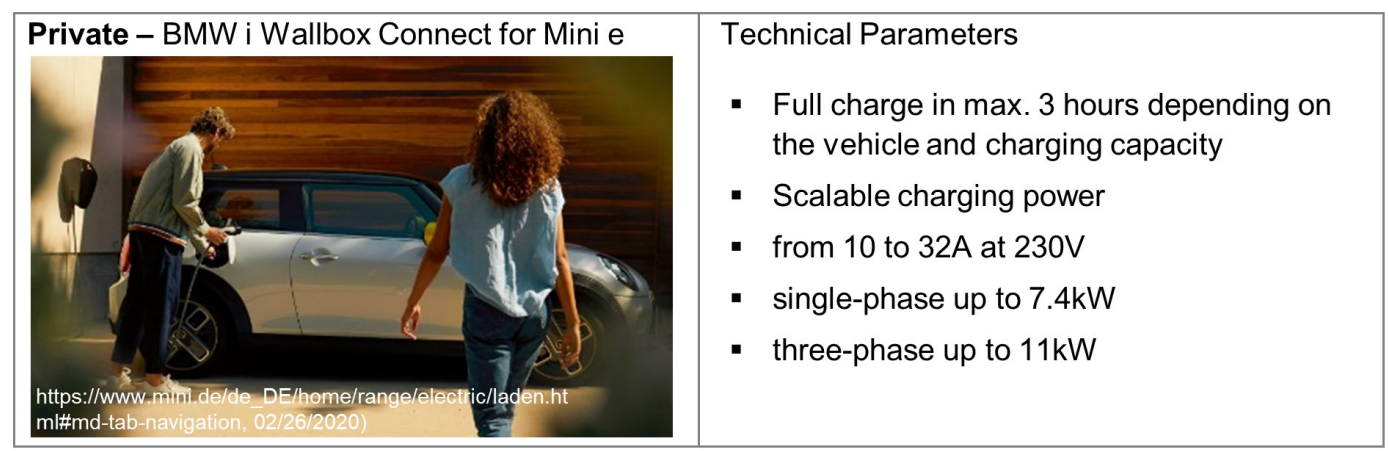

Figure 2. Wallbox: Charging at home. 


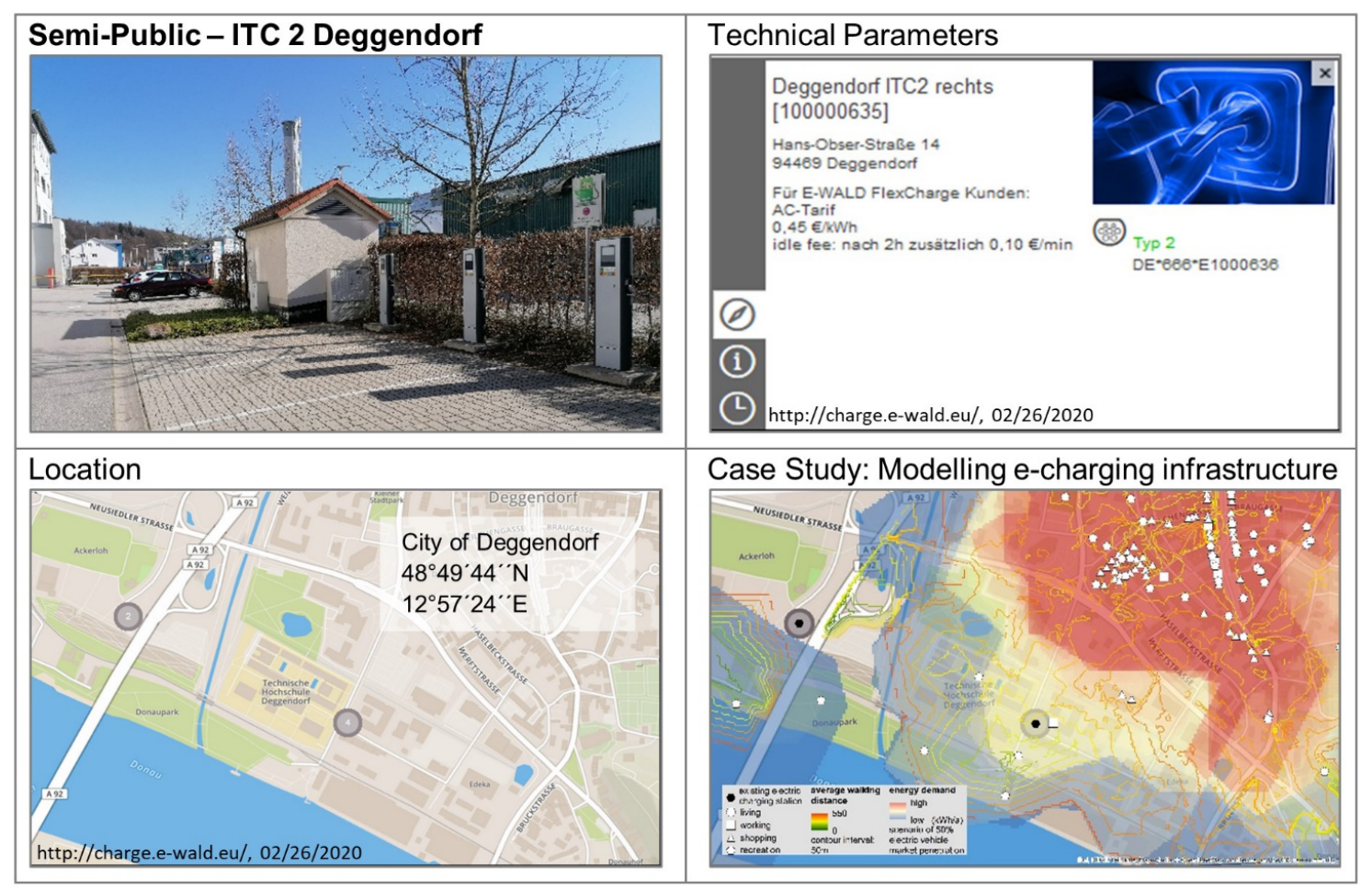

Figure 3. Example for CS in semi-public areas.

meet the social need for increased environmental awareness, especially in Germany. In addition to this 'greenwashing,' companies also want to demonstrate their innovative strength. Although only a few CSs are currently being built, the location modelling shows a high need for charging capacity as the penetration rate of EVs increases. In the private and semi-public sector, however, demand is the decisive factor. Therefore, companies will only expand and provide the charging infrastructure when there is a corresponding demand, i.e., a sufficient number of EVs using the parking site.

\subsection{Public Context}

Municipalities and cities can design and plan the charging points that fall into the spatial category of public space. As in the semi-public context, the charging points are based mostly on existing parking sites at municipal facilities or in public spaces, for example along streets. The parking sites can be permanently accessible, such as at park and ride parking spaces near the train station (Figure 4) or can be limited in time, such as in public parking sites. Parking and charging can be offered free of charge or as a paid service. The electricity requirement depends on the number of parking sites and their frequency. Similar to the large parking areas in the semipublic space, new electricity infrastructure is usually required here including both new CSs and new electricity networks. They need to be able to provide the large amount of electricity a CS requires. The need for a high energy capacity results from the parking spaces being used mainly at certain peak times as well as the fact that, in transport patterns associated with retail and amenity purchases, cars are usually only parked for short periods. Therefore, the demand for fast charging, which consumes very large amounts of electricity in a short period, increases.

\subsection{Case Study}

The Case Study region is located in the southeast of Germany, including eight administrative districts (NUTS-3): Cham, Deggendorf, Freyung-Grafenau, Passau, city of Passau, Regen, city of Straubing and StraubingBogen, covering a total of $7,200 \mathrm{~km}^{2}$. The CS modelling method applied in this example was developed by Pagany, Marquardt, and Zink (2019). Other similar approaches include different target criteria such as the minimization of trip length or travel time, spatial hotspots of charging demand following population distributions or driving path densities, traffic, or a mix of criteria (i.e., Namdeo, Tiwary, \& Dziurla, 2014; Viswanathan et al., 2016; Wagner, Brandt, \& Neumann, 2014). Although the results of these different models may be influenced by their methodology, they are all based on driver behaviour and adapted to specific contexts.

In the case study presented here, the catchment areas around various points of interest of the public and semi-public sector are calculated and combined in a gravitational model with GPS data. The calculated scenario assumes a $50 \%$ penetration rate of EVs and slow-CSs. The necessary datasets were extracted from OpenStreetMap in 2016 and were used for the spatial calculation of the catchment areas (Geofabrik, 2016). In addition to the 


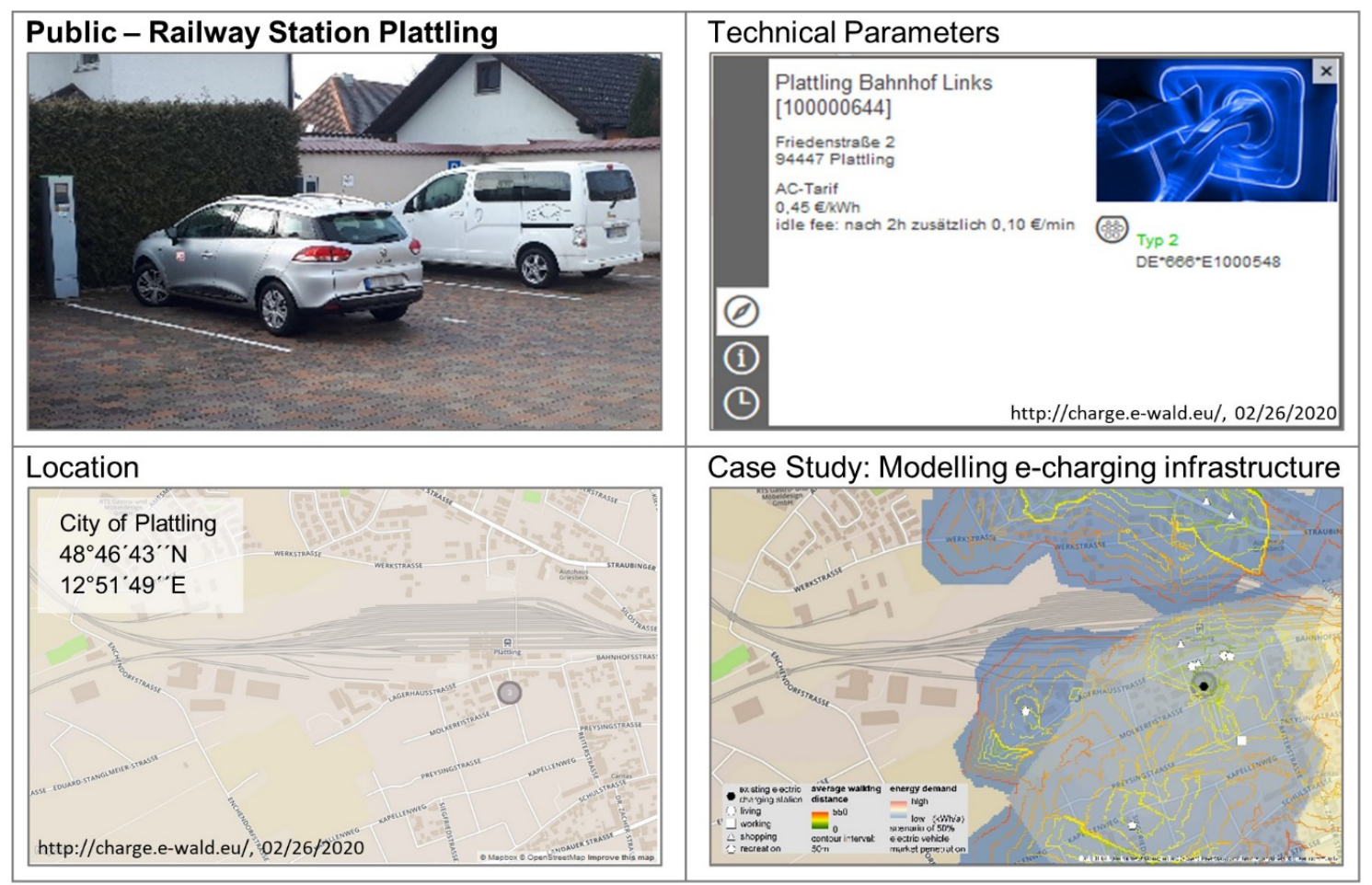

Figure 4. Example of a CS in a public area.

spatial distances, the frequency of use and the length of stay at the locations are important factors to consider. For this purpose, user groups according to age, gender, family situation, leisure behaviour, and occupation, are defined and set in relation to the respective points of interest. The more often and longer a user group stays at a location, the higher the location's importance is weighted regarding the need for CS. Finally, within the modelled catchment areas, specific CS locations can be identified using the preferred walking distances of each user group between their parking and destination points of interest.

Figures 3 and 4 present results of the modelling approach for exemplary areas in the case study region regarding the semi-public or public categories. The charging demand ( $\mathrm{kWh} / \mathrm{a}$ ) is graded in colour and the average walking distances are drawn as contour lines $(m)$. The optimum location of a CS within the catchment area is identified based on high electricity demand and short walking distances between parking/charging the vehicle and the destination. The results can be helpful in discussing the new infrastructure patterns either for already existing CSs, as in Figures 3 and 4 with CSs from E-WALD GmbH, or for the planning of new CSs.

Results of this analysis indicate that CS sites are not installed with a consumer view but at the location most interesting to the financing party. This means that the private sector installs a semi-public CS considering what best suits their own interest, thus they are installed where their own customers park. It seems that earning money with the installed CS is just a secondary goal compared to the main objective of demonstrating innovation and caring for the environment of customers and employees. Public CSs are also not always set up at places that suit the consumers best but where it is most representative. Many CSs are for example installed close to town halls rather than to first provide the railway station with suitable CSs. This result shows how difficult it is for the government to influence the organization of the development of the CS infrastructure. Therefore, the question of the initial impulse to implement the transformation towards electric mobility remains. Do EVs first need to be established in the market to ensure profitable operation of the charging infrastructure and to make sure that the parties install CSs for profitability rather than for image reasons, or must the charging infrastructure first be set up so that charging is as extensive for EVs as it is for fossil-fuelled vehicles? Is it necessary for the government to provide a coordinated action so as not to waste CS resources that only serve to improve brand image? What mechanism or policy can allow for the reorganization of the transportation system under public-private coordination? These dilemmas go hand in hand with the question of government impulses for electric mobility. In the German public discussion, especially dominated by the so-called fear of range and the everyday suitability of electric mobility, there are state subsidies for the purchase of EVs and in parallel the promotion of the installation of CSs.

\section{Purchase Subsidies in Germany}

In addition to the existence of economies of scale and barriers to entry, one of the main characteristics of EV charg- 
ing networks is the need to have a critical mass of users to make the system sustainable. This makes the existence of a sufficiently large load network necessary in order to compensate for the disincentives associated with current EVs' reduced range when compared to combustion engines. If these hypotheses are true, then it is possible to claim that an insufficient transport network affects EV adoption. However, it is difficult to empirically prove this statement because both variables, availability and characteristics of CSs and EV adoption rates, influence each other. Research based on case studies and comparative studies applying synthetic control units has been an active area of research in policy evaluation and can help to solve this endogeneity problem. We examine the development of the EV market in Germany using the synthetic control method in order to assess the effect of purchase subsidies on BEV and PHEV car registrations. We assume that with the introduction of the subsidies the number of BEVs should increase. Furthermore, to establish the validity of the results, we analyze the impact of the same subsidy policy on PHEV vehicle purchases which have an internal combustion engine as backup included and are therefore much less affected by the lack of CSs.

The synthetic control method is a powerful approach for comparative case studies when there is one or only a few treated units, and only aggregated outcomes are observable (Abadie et al., 2010, 2015; Abadie \& Gardeazabal, 2003). The approach allows the construction of accurate counterfactuals of the country of interest using a control group of donor countries not subjected to the policy intervention under consideration. The identifying assumption in the present context is that EV registrations in Germany would have evolved in the same manner as in their synthetic counterfactuals in a hypothetical world without the introduction of the purchase subsidy. Formally, following Abadie and Gardeazabal (2003), under the synthetic control we suppose that there are $\mathrm{J}+1$ countries where $\mathrm{J}=1$ denotes Germany and $\mathrm{j}=2-\mathrm{J}+1$ includes a group of untreated countries. A total of 12 countries are observed in the sample. The treatment country is Germany and the countries in the control units (donor pool) are different European countries that did not implement purchase subsidies. In addition, $T_{0}$ is defined as the time of treat- ment. For Germany, data are available on the actual emission trajectory $\left(\mathrm{Y}_{1 \mathrm{t}}\right)$, and the counterfactual emissions that would have occurred if Spain had not been subject to treatment $\left(\mathrm{Y}_{1 \mathrm{~N}}^{\mathrm{N}}\right.$ for $\left.\mathrm{t}>\mathrm{T}_{0}\right)$. For Germany, an estimate of $Y_{1 \mathrm{t}}^{\mathrm{N}}$ has to be found to obtain an estimate of the treatment effect $\propto_{i t}$ :

$$
\propto_{i t}=Y_{1 \mathrm{t}}-Y_{1 \mathrm{t}}^{\mathrm{N}} \text {. }
$$

The differences in the outcome variables between Germany and its synthetic counterfactuals following the treatment measures is the causal effect of the purchase subsidy if the synthetic control assumptions hold. To estimate $\propto_{i t}$, it is proposed that a number of observed characteristics of the countries in the donor group are made use of. The underlying idea is to find weights $\mathrm{W}=\left(\mathrm{w}_{2}-\mathrm{w}_{\mathrm{j}+1}\right)^{\prime}$, with $\mathrm{w}_{\mathrm{j}} \geq 0$ for $\mathrm{j}=2-\mathrm{J}+1$ and $\mathrm{w}_{\mathrm{j}}=1, \mathrm{j}=2_{\mathrm{j}+1}$, so that the weighted average of all countries in the donor group resembles the treated country (Germany) with respect to BEV and PHEV in the pre-intervention period and a number of other relevant aspects used as covariates (Z). In our application, the counterfactual outcome is generated as a weighted average of the following covariates: mean net income, passenger vehicle stock, motorization rates, new passenger vehicle registrations, and electricity prices (Table 1). The information on new car registrations was retrieved from the European Automobile Manufacturers' Association database in July 2019 (European Automobile Manufacturers' Association, 2019). Together with this data, and in order to generate the synthetic control unit from the group of countries of the pool, we retrieved the data from Eurostat (Eurostat, 2019) databases for the selected period.

The European Alternative Fuels Observatory (2020) summarizes the policies applied to the topic of electromobility in most of the European member states. They furthermore provide information on the adoption of EVs, the sum of purchased cars per country as well as facts on the development status of the CS infrastructure. The data set encompasses the period 2010-2017 (see Figures 5 and 6). We, therefore, cover five years before the introduction of the subsidy (pre-treatment) and two years afterwards (post-treatment). The control group includes Bulgaria, Switzerland, Czech Republic, Estonia,

Table 1. Summary statistics.

\begin{tabular}{llllll}
\hline Variable & Source & N & Min & mean & max \\
\hline Population & Eurostat & 96 & 1314870 & 51081276 & 325446443 \\
Net Income & Eurostat & 96 & 3276 & 18113 & 74585 \\
Vehicle stock & ACEA & 96 & 552680 & 20899574 & 129053000 \\
Motorization Rate & Eurostat & 96 & 0.3581 & 52.6135 & 614.0950 \\
BEV Registrations & EAFO & 96 & 0.0 & 4082.8 & 86700.0 \\
PHEV registrations & EAFO & 96 & 0.0 & 3689.4 & 72900.0 \\
Passenger vehicles registrations & ACEA & 96 & 6365 & 1129997 & 7689110 \\
Electricity Price & Eurostat & 96 & 0.08215 & 0.15614 & 0.30480 \\
Purchase subsidy & EAFO & 96 & 0.0 & 373.9 & 4000.0 \\
\hline
\end{tabular}




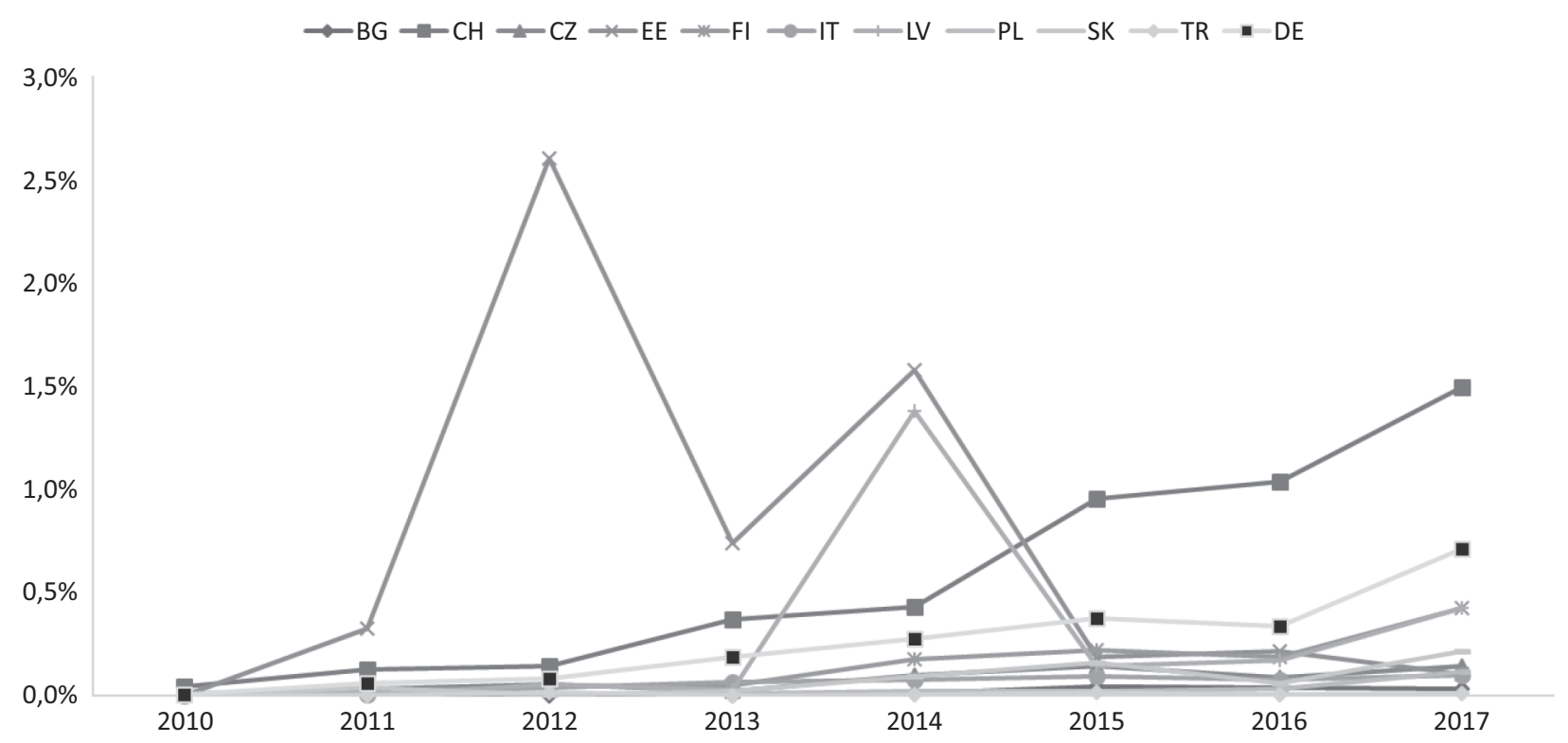

Figure 5. Share of BEV vehicle registrations in selected countries.

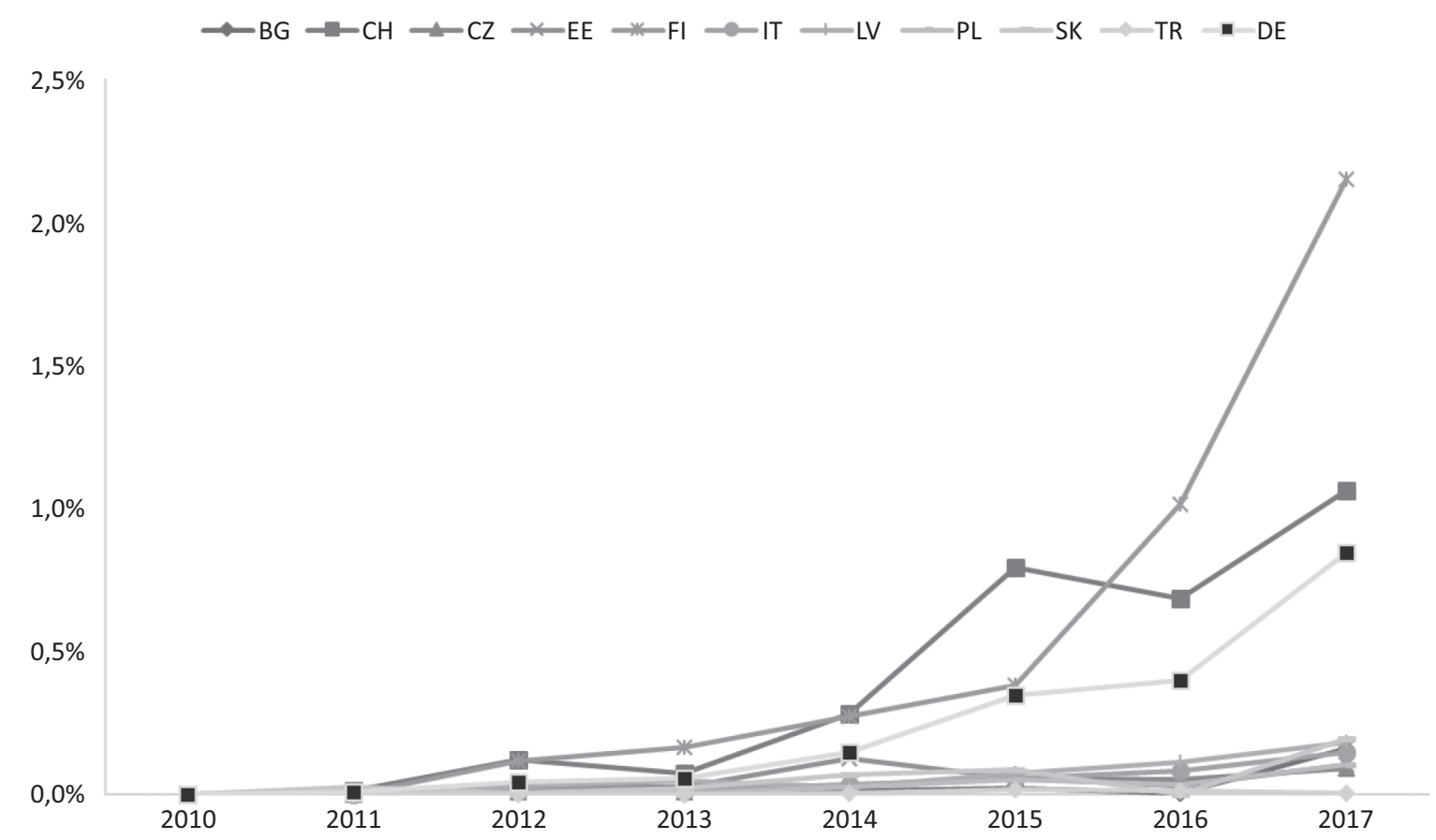

Figure 6. Share of PHEV vehicle registrations in selected countries.

Finland, Italy, Latvia, Poland, Slovakia, and Turkey. Unlike Germany, these countries have very limited or no subsidies for the purchase of EVs.

The results in Figure 7 (a) and (c) show the generated synthetic unit for both the share of BEV and the share of PHEV together with the vehicles registered in Germany and the gaps between the EV car registrations and the synthetic unit. The differences between the dashed lines show that there is a sufficient match between the trends in the outcome variable for synthetic and treated countries in the pre-treatment period for the share of PHEVs in total registrations. In particular, there was a consider- able increase in car registrations of this type of vehicles from 2015 onwards for PHEV but a very low increase in the case of BEVs. This increase denotes a positive effect on sales of PHEV that can be associated with the introduction of the purchase subsidy because no other factor affected the German PHEV market during 2016 and 2017. In both cases, we observed that the countries of the synthetic unit are composed of the same countries with different percentages (Table 2). The unit includes Finland, Switzerland, Poland, and Slovakia, a mix of countries with developed but small EV markets and countries with much smaller markets than Germany. 
Table 2. Donor pool weights for synthetic control units.

\begin{tabular}{lcc}
\hline Example & Share of BEVs & Share of PHEVs \\
\hline Bulgaria & 0.000 & 0.000 \\
Switzerland & 0.279 & 0.335 \\
Czech Republic & 0.000 & 0.000 \\
Estonia & 0.014 & 0.000 \\
Finland & 0.269 & 0.090 \\
Italy & 0.000 & 0.000 \\
Latvia & 0.000 & 0.000 \\
Poland & 0.209 & 0.230 \\
Slovakia & 0.229 & 0.345 \\
Turkey & 0.000 & 0.000 \\
losss w & 0.115 & 0.083 \\
\hline
\end{tabular}

Since the synthetic control does not provide classic standard errors for making statistical inferences, Abadie and Gardeazabal (2003) suggest performing placebo or permutation tests. The underlying idea is to estimate counterfactual emission trajectories for countries in the donor group. In an ideal world where the perfect analogue of the treated country is available in the donor community, no treatment effect would be found for any country in the donor group independent of the years after treatment. However, in practice, effects of the placebo treatment will always be found, at least to some extent. As a result, only the actual effect of the treatment is considered to be statistically significant if it is significantly greater than the effects of the treatment within the synthetic control unit. Figure 7 (b) and (d) include a series of placebo-tests, calculated using the control unit (a)

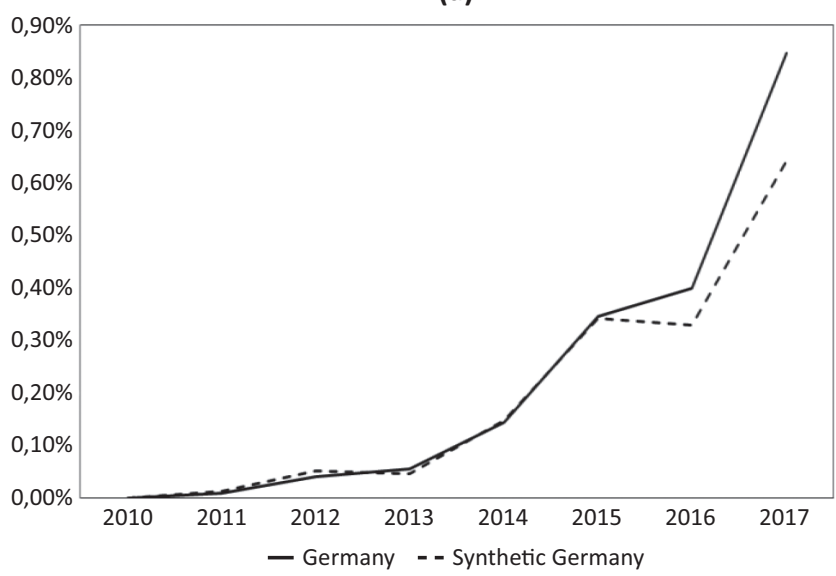

(c)

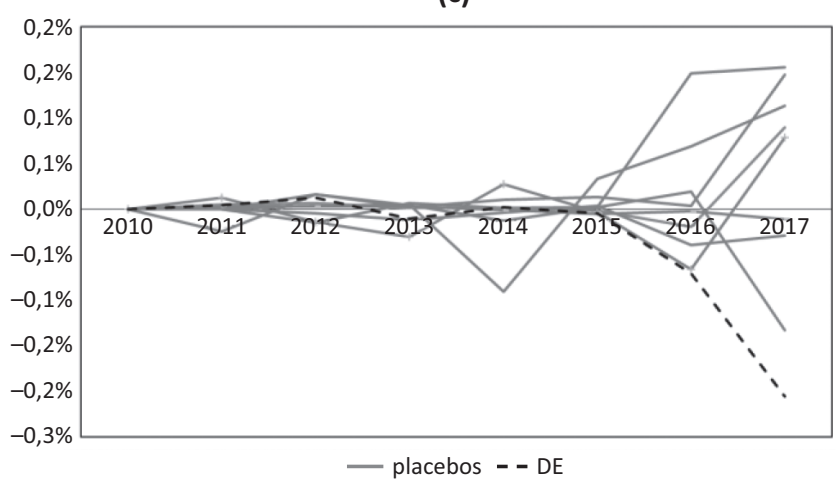

(b)

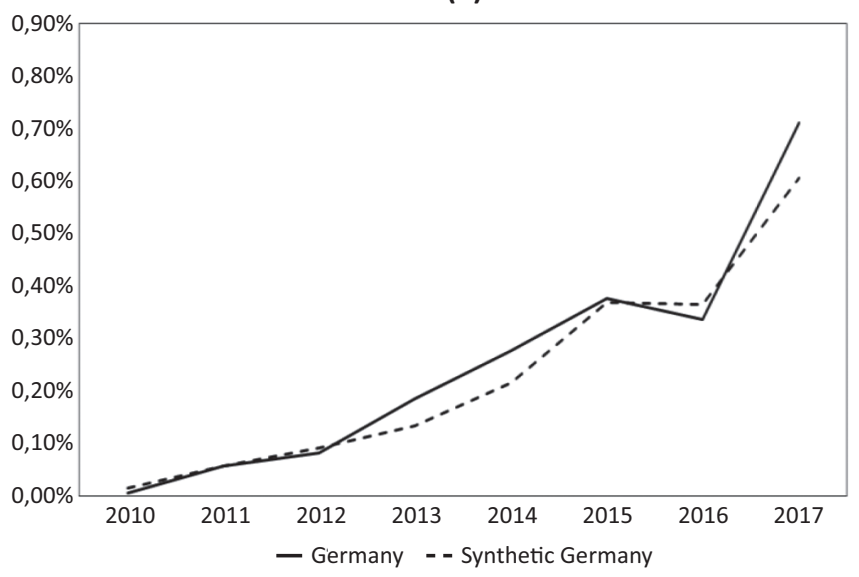

(d)

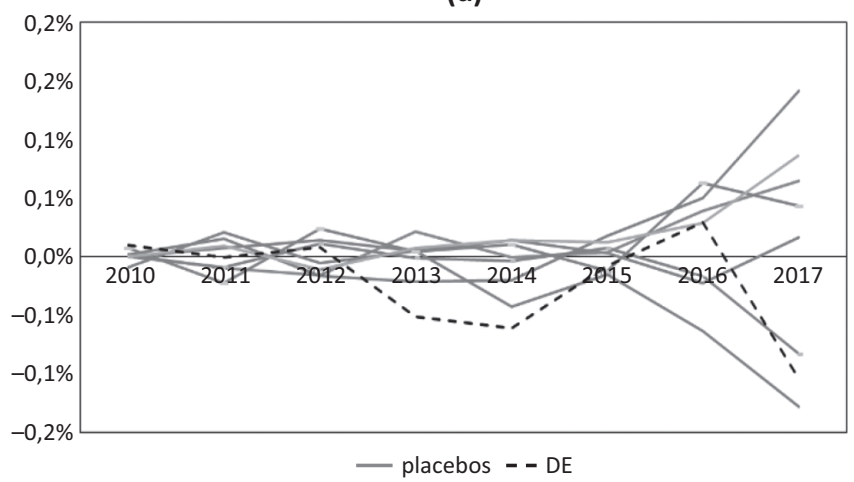

Figure 7. Synthetic control result for: (a) PHEV registrations in Germany and synthetic Germany; (b) Difference between placebo test for PHEV registrations, synthetic Germany, and actual Germany PHEV registrations ( $x$ axis line); (c) BEV registrations in Germany and synthetic Germany; (d) Difference between placebo test for BEV registrations, synthetic Germany, and actual Germany BEV registrations (x axis line). 
for PHEV and BEV registrations respectively. The results show that none of the other countries display results as significant as those in Germany for PHEV sales. They thus reinforce the hypothesis that the positive effect from 2015 onwards is due to the introduction of the subsidy and not due to any other intervention.

These results stand in contrast with BEV results. The pre-treatment periods of the synthetic control unit do not provide such a good fit as in the case of PHEVs. For the post-treatment period, the results show a much lower increase in sales than in the case with PHEVs, which means that the subsidy has not had such a positive effect as expected. One important factor to consider is the role of the private sector. In 2010, consumers in the European market could choose between $15 \mathrm{BEV}$ models but only one PHEV model. In 2017, the number of PHEV models available on the market increased to 33 , while there were $28 \mathrm{BEV}$ models. This low increase in BEV sales may be partly due to a combination of causes such as the private sector's increased ability to integrate new technologies into production chains, to exploit existing knowhow or to address barriers to acceptance. Nevertheless, the limited availability of overall EV models affected the whole European market.

Another possible reason for these results has to do with the technical characteristics of both cars. PHEV drivers are not affected by the lack of a recharging infrastructure or the long charging times of the electric batteries thanks to the incorporation of a combustion engine together with the electric motor. The analysis presented in Section 3 shows that in most cases the available recharging infrastructure is reduced to the private household CSs. This is due to the lack of fast CSs at locations with higher parking demand, encouraging the use of PHEV models with which customers can compensate for the lack of a complete and geographically well-distributed charging network. At the same time, the need for a home CS creates a potential entry barrier for urban users who do not reside in single-family residential neighbourhoods. This, in turn, reduces the profitability of existing EVs and discourages investment in new infrastructure.

\section{Conclusion}

The use of EVs is presented as the main option to reduce $\mathrm{CO}_{2}$ emissions in the transport sector. The transition to a model of mobility not based on the use of fossil fuels requires replacing the vehicle fleet and therefore a high level of investment to encourage change in both the infrastructure and vehicles. To this end, since early 2010, Germany implemented a series of measures to promote the use of EVs, including purchase subsidies and the development of charging infrastructures. In order to understand the effect of these incentives, this article analyzed the impact of the purchase subsidy for both, the BEV and PHEV market sectors by analyzing the spatial distribution of CSs. The results show that the subsidy has had a limited impact on the growth of the EV market. It has mainly affected the purchase of PHEVs rather than the purchase of BEVs. Moreover, the distribution of the CS infrastructure installed does not correspond to the results of the calculated spatial distribution model but seems to be based more on image marketing.

This poses a number of implications for public policy. Firstly, the current incentives are mainly dedicated to subsidizing EV buyers who would have bought EVs anyway. The cost of EVs in Europe was in 2019 at least 40\% higher than combustion engine vehicles and the high price compared to common fossil engines is one of the identified barriers for EV adoption in Germany. In our analysis, the German counterfactual shows that in the case of BEVs, sales without subsidy would have been very similar to sales after the introduction of the subsidy. Also, the increase in the PHEV market is relatively small compared to the case of no purchase subsidies. This limited effect may be explained by the small size of the subsidy compared to the total price of the EV. Secondly, with the analyzed subsidy, the government is encouraging the use of PHEVs at the cost of EVs. PHEVs, however, have a much lower greenhouse gas reduction potential than EVs, which reduces the positive effect sought by the policy. Previous studies have shown that EV buyers make their purchase decisions based on ideological grounds relating to environmental sensitivity. Simultaneously introducing a subsidy for the purchase of BEVs and PHEVs might indicate to the purchaser that both types of EVs have the same 'environmental bonus' associated with the transition. The overall goal of the purchase subsidy is a reduction in emissions resulting from the road transport sector by fostering the adoption of EVs. However, such a transformation of the vehicle fleet can only contribute to this goal if the electricity consumed by EVs is generated through renewable sources. In the case of Germany today, more than $30 \%$ of electricity still comes from coal. Therefore, only if the electricity transition towards more renewable energy carriers is supported can a reduction of emissions from the road transport sector, and thus the overall goal of the policy under investigation, be achieved.

Regarding the development of charging infrastructures both, municipalities and companies are hesitant when it comes to expanding an adequate electric charging infrastructure in public spaces. Although, numerous concepts of how the new supply infrastructure will look like in the future exist, investments are not being made due to the lack of economic profitability of CSs. The expansion is usually limited to model projects marketed in the media or to a few very innovative companies and municipalities. Moreover, as CSs are subsidized, companies may be using the installation of charging infrastructures primarily for image and marketing purposes to meet the social need for increased environmental awareness. This result is especially important because the development model of the load-bearing infrastructure is characterized by being decentralized and spatially dispersed. As nation- 
wide supply for a large number of EVs is not yet available, an underdeveloped network of these characteristics may be nourishing negative synergies. It is, therefore, necessary to understand the extent to which the uncoordinated installation of the CS system moves away from the location models and how it may be affecting the adoption of EV.

PHEVs can moreover cause the nationwide vehicle fleet's conversion to have a much lesser impact on greenhouse gas emissions than BEVs are likely to. If so, the renewal of the fleet would have a minor negative effect on the automobile industry, which could continue to sell combustion engine cars and continue to make a profit on their investment in models with combustion technology. On the other hand, this could make it more difficult for new competitors to enter the market and for new mobility concepts to be developed, based on a more radical and profound transformation of both consumer habits and the transport infrastructure. As far as CS infrastructure is concerned, the increase in PHEVs may generate a negative effect which must be taken into account and which may appear in the next few years. These vehicles do not need the use of the CS network so they may be discouraging its use, as well as its expansion and the expected benefits of the transition.

From these conclusions, one can deduce that neither an increasing charging infrastructure nor an EV subsidy policy are likely to be sufficient to accelerate a transition per se in Germany. Both policies must be integrated into a broader vision of energy transition and should avoid positions that reduce the anticipated effects to trade-offs between EV or CS support. The combination of an important network of actors and interests makes Germany very different from other European countries where the EV transitions are faster (for a review, see Sovacool et al., 2020). Further research is necessary to generate and analyze more data concerning the dynamic impacts of both subsidies and other influencing variables have and the role of these actors on the impact of these policies. The current lack of data is the main inhibitor to further understanding the dynamically intertwined relationship of the EV market with the charging infrastructure, the electricity market and consumer behaviour. Nevertheless, factors such as the potential sites of electricity generation, its impact on CS development, and the extent to which policies to reduce emissions through electromobility depend on the transition towards renewables should be analyzed in more depth.

\section{Acknowledgments}

The presented methodology and results are extracted from the research and development project 'eRoad Písek-Deggendorf,' funded by the European Union and the European Regional Development Fund through the program 'ETZ Freistaat Bayern-Tschechische Republik 2014-2020' (Interreg V). Project partners are Technologické centrum Písek (lead partner), E-WALD
$\mathrm{GmbH}$ (project partner), and the associated partners, the City of Písek and e-Šumava.cz.

\section{Conflict of Interests}

The authors declare no conflict of interests.

\section{References}

Abadie, A., Diamond, A., \& Hainmueller, J. (2010). Synthetic control methods for comparative case studies: Estimating the effect of California's tobacco control program. Journal of the American Statistical Association, 105, 493-505. https://doi.org/10.1198/jasa. 2009.ap08746

Abadie, A., Diamond, A., \& Hainmueller, J. (2015). Comparative politics and the synthetic control method. American Journal of Political Science, 59, 495-510. https://doi.org/10.1111/ajps.12116

Abadie, A., \& Gardeazabal, J. (2003). The economic costs of conflict: A case study of the Basque Country. American Economic Review, 93, 113-132. https://doi.org/ $10.1257 / 000282803321455188$

AG Energiebilanzen e.V. (2020). Bruttostromerzeugung nach Energieträgern [Gross electricity generation by energy source]. Berlin: AGEB. Retrieved from https://ag-energiebilanzen.de/index.php?article_ id=29\&fileName=ageb-strerz2019_18122019.pdf

Andrenacci, N., Ragona, R., \& Valenti, G. (2016). A demand-side approach to the optimal deployment of electric vehicle charging stations in metropolitan areas. Applied Energy, 182, 39-46. https://doi.org/ 10.1016/j.apenergy.2016.07.137

Athey, S., \& Imbens, W. G. (2017). The state of applied econometrics: Causality and policy evaluation. Journal of Economic Perspectives, 31(2), 3-32.

Blaschke, T., Biberacher, M., Gadocha, S., \& Schardinger, I. (2013). 'Energy landscapes': Meeting energy demands and human aspirations. Biomass and Bioenergy, 55, 3-16. https://doi.org/10.1016/j.biombioe. 2012.11.022

Bosch, S., Rathmann, J., \& Schwarz, L. (2019). The energy transition between profitability, participation and acceptance: Considering the interests of project developers, residents, and environmentalists. Advances in Geosciences, 49, 19-29. https://doi.org/10.5194/ adgeo-49-19-2019

Campaña, M., \& Inga, E. (2019). Optimal allocation of public charging stations based on traffic density in smart cities. Paper presented at the IEEE Colombian Conference on Applications in Computational Intelligence (ColCACl), Barranquilla, Colombia.

Collier, D. (1993). The comparative method. In A. Finifter (Ed.), Political science: The state of the discipline II (pp. 105-119). Washington, DC: American Political Science Association.

Die Bundesregierung. (2009). Nationaler Entwicklungsplan Elektromobilität der Bundesregierung [National 
development plan of electro mobility of the federal government]. Berlin: Die Bundesregierung. Retrieved from https://www.bmu.de/fileadmin/bmuimport/files/pdfs/allgemein/application/pdf/nep_ 09_bmu_bf.pdf

European Alternative Fuels Observatory. (2020). European Alternative Fuels Observatory EU legislation and policies. European Alternative Fuels Observatory. Retrieved from https://www.eafo.eu

European Automobile Manufacturers' Association. (2019). European Automobile Manufacturers' Association statistics: Registration figures. European Automobile Manufacturers' Association. Retrieved from https://www.acea.be/statistics

Eurostat. (2019). Eurostat database. Eurostat. Retrieved from https://ec.europa.eu/eurostat/data/database

Geels, F. W. (2002). Technological transitions as evolutionary reconfiguration processes: A multi-level perspective and a case-study. Research Policy, 31(8/9), 1257-1274.

Geofabrik. (2016). OpenStreetMap database. Geofabrik. Retrieved from http://www.geofabrik.de

Girardi, P., Gargiulo, A., \& Brambilla, P. C. (2015). A comparative LCA of an electric vehicle and an internal combustion engine vehicle using the appropriate power mix: the Italian case study. The International Journal of Life Cycle Assessment, 20(8), 1127-1142.

International Electrotechnical Commission. (2020). World plugs by location. International Electrotechnical Commission. Retrieved from https:// www.iec.ch/worldplugs/list_bylocation.htm

KBA. (2020). Pkw-Bestand in Deutschland nach Kraftstoffarten 1.1.2017-1.1.2020 [Number of cars in Germany by type of fuel 1.1.2017-1.1.2020]. Statista. Retrieved from https://de.statista.com/ statistik/daten/studie/4270/umfrage/pkw-bestandin-deutschland-nach-kraftstoffarten

Kester, J., Noel, L., de Rubens, G. Z., \& Sovacool, B. K. (2018). Policy mechanisms to accelerate electric vehicle adoption: A qualitative review from the Nordic region. Renewable and Sustainable Energy Reviews, 94, 719-731.

Kester, J., Sovacool, B., de Rubens, G. Z., \& Noel, L. (2020). Novel or normal? Electric vehicles and the dialectic transition of Nordic automobility. Energy Research \& Social Science, 69. https://doi.org/10.1016/j.erss. 2020.101642

Langbroek, J. H. M., Franklin, J. P., \& Susilo, Y. O. (2016). The effect of policy incentives on electric vehicle adoption. Energy Policy, 94, 94-103. https://doi.org/ 10.1016/j.enpol.2016.03.050

Lieven, T. (2015). Policy measures to promote electric mobility: A global perspective. Transportation Research Part A: Policy and Practice, 82, 78-93. https:// doi.org/10.1016/j.tra.2015.09.008

Lijphart, A. (1971). Comparative politics and the comparative method. The American Political Science Review, 65(3), 682-693.
Lin, X., \& Sovacool, B. K. (2020). Inter-niche competition on ice? Socio-technical drivers, benefits and barriers of the electric vehicle transition in Iceland. Environmental Innovation and Societal Transitions, 35, 1-20. https://doi.org/10.1016/j.eist.2020.01.013

Namdeo, A., Tiwary, A., \& Dziurla, R. (2014). Spatial planning of public charging points using multidimensional analysis of early adopters of electric vehicles for a city region. Technological Forecasting and Social Change, 89, 188-200. https://doi.org/ 10.1016/j.techfore.2013.08.032

Pagany, R., Marquardt, A., \& Zink, R. (2019). Electric charging demand location model: $A$ user-and destination-based locating approach for electric vehicle charging stations. Sustainability, 11(8). https:// doi.org/10.3390/su11082301

Pagany, R., Ramirez Camargo, L., \& Dorner, W. (2018). A review of spatial localization methodologies for the electric vehicle charging infrastructure. International Journal of Sustainable Transportation, 13(6), 433-449. https://doi.org/10.1080/15568318. 2018.1481243

Rae, C., Kerr, S., \& Maroto-Valer, M. (2020). Upscaling smart local energy systems: A review of technical barriers. Renewable and Sustainable Energy Reviews, 131. https://doi.org/10.1016/j.rser.2020.110020

Richardson, D. (2013). Electric vehicles and the electric grid: A review of modeling approaches, impacts, and renewable energy integration. Renewable and Sustainable Energy Reviews, 19, 247-254. https://doi. org/10.1016/j.rser.2012.11.042

Riesz, J., Sotiriadis, C., Ambach, D., \& Donovan, S. (2016). Quantifying the costs of a rapid transition to electric vehicles. Applied Energy, 180, 287-300. https:// doi.org/10.1016/j.apenergy.2016.07.131

Rohr, C., Lu, H., Thiel, C., Smyth, A., Kelleher, L., Harrison, G., \& Gómez Vilchez, J. (2017). Quantifying the factors influencing people's car type choices in Europe results of a stated preference survey. Brussels: Joint Research Centre.

Sovacool, B. K. (2017). Experts, theories, and electric mobility transitions: Toward an integrated conceptual framework for the adoption of electric vehicles. Energy Research \& Social Science, 27, 78-95.

Sovacool, B. K., \& Hirsh, R. (2009). Beyond batteries: An examination of the benefits and barriers to plug-in hybrid electric vehicles (PHEVs) and a vehicle-to-grid (V2G) transition. Journals \& Books, 37, 1095-1103. https://doi.org/10.1016/j.enpol.2008.10.005

Sovacool, B. K., Kester, J., Noel, L., \& de Rubens, G. Z. (2020). Actors, business models, and innovation activity systems for Vehicle-to-Grid (V2G) technology: A comprehensive review. Renewable and Sustainable Energy Reviews. https://doi.org/10.1016/j.rser.2020. 109963

United Nations. (2015). Paris agreement. Washington, DC: United Nations. Retrieved from https:// unfccc.int/files/essential_background/convention/ 
application/pdf/english_paris_agreement.pdf

Verband der Automobilindustrie. (2019). Position: Recommendations for a successful ramp-up of charging infrastructure for electric vehicles by 2030. Verband der Automobilindustrie. Retrieved from https://www.vda.de/en/services/Publications/ position-paper-on-charging-infrastrucure.html

Viswanathan, V., Zehe, D., Ivanchev, J., Pelzer, D., Knoll, A., \& Aydt, H. (2016). Simulation-assisted exploration of charging infrastructure requirements for electric vehicles in urban environments. Journal of Computational Science, 12, 1-10. https://doi.org/10.1016/ j.jocs.2015.10.012

Wagner, S., Brandt, T., \& Neumann, D. (2014). Smart city planning: Developing an urban charging infrastructure for electric vehicles. Paper presented at the 22nd European Conference on Information Systems, Tel Aviv, Israel.

Wirges, J. (2016). Planning the charging infrastructure for electric vehicles in cities and regions. KIT Scientific Publishing. http://dx.doi.org/10.5445/KSP/ 1000053253

Zink, R. (2015). Les stratégies énergétiques régionales en Basse-Bavière face aux enjeux économiques, environnementaux et sociaux [Regional energy strategies in Lower Bavaria facing economic, environmental and social challenges]. Revue Géographique de l'Est, 55.

\section{About the Authors}

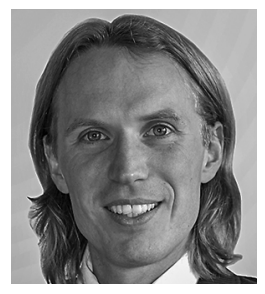

Roland Zink received his Doctorate at the University of Passau on the subject of the transition of the energy sector and the design of sustainable energy supplies under a spatial perspective. Since 2013, he has been Professor of Spatial Sciences and Information Systems at DIT and Scientific Head of the research group 'Geoinformatics' at the Technology Campus Freyung. In addition to further developing spatio-temporal energy models, his current research focuses on innovative opportunities for public participation in spatial planning processes through new media and the link between digitization and sustainable development.

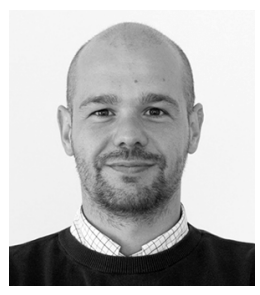

Javier Valdes is a Senior Scientist at DIT. He studied economics at the Universidad Autónoma de Madrid and holds a PhD from the University of Ferrara and the University of Parma, and a Master of Economics, Law and Business from the Université Grenoble Alpes. His research focuses on applied economics, and spatio-temporal analysis with a focus on energy economics and the economics of innovation.

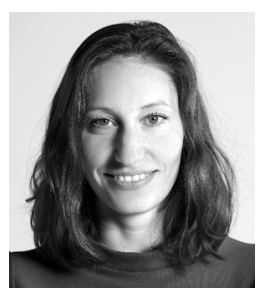

Jane Wuth is a Researcher at the Institute for Applied Informatics in Freyung, a Technology Campus of the Deggendorf Institute of Technology (Germany). Her research focuses on the economic side of innovation and digital technologies. She currently is pursuing her $\mathrm{PhD}$, researching start-ups which use innovative technologies in rural regions. Using spatial econometric models, she analyses start-up digitization and development behaviour and their dependence on regionally influencing factors. 